\title{
Deriving in situ phytoplankton absorption for bio-optical productivity models in turbid waters
}

Matthew J. Oliver, Oscar Schofield, Trisha Bergmann, and Scott Glenn

Institute of Marine and Coastal Sciences, Rutgers University, New Brunswick, New Jersey, USA

Cristina Orrico and Mark Moline

Biological Sciences Department, California Polytechnic State University, San Luis Obispo, California, USA

As part of Hyperspectral Coupled Ocean Dynamics Experiment, a high-resolution hydrographic and bio-optical data set was collected from two cabled profilers at the Long-Term Ecosystem Observatory (LEO). Upwelling-and downwelling-favorable winds and a buoyant plume from the Hudson River induced large changes in hydrographic and optical structure of the water column. An absorption inversion model estimated the relative abundance of phytoplankton, colored dissolved organic matter (CDOM) and detritus, as well as the spectral exponential slopes of CDOM and detritus from in situ WET Labs nine-wavelength absorption/attenuation meter (ac-9) absorption data. Derived optical weights were proportional to the parameter concentrations and allowed for their absorptions to be calculated. Spectrally weighted phytoplankton absorption was estimated using modeled spectral irradiances and the phytoplankton absorption spectra inverted from an ac-9. Derived mean spectral absorption of phytoplankton was used in a bio-optical model estimating photosynthetic rates. Measured radiocarbon uptake productivity rates extrapolated with water mass analysis and the bio-optical modeled results agreed within $20 \%$. This approach is impacted by variability in the maximum quantum yield $(\Phi)$ and the irradiance light-saturation parameter (Ek(PAR)). An analysis of available data shows that $\Phi$ max variability is relatively constrained in temperate waters. The variability of $\mathrm{Ek}(\mathrm{PAR})$ is greater in temperate waters, but based on a sensitivity analysis, has an overall smaller impact on water-column-integrated productivity rates because of the exponential decay of light. This inversion approach illustrates the utility of bio-optical models in turbid coastal waters given the measurements of the bulk inherent optical properties.

\section{Introduction}

There is growing evidence that anthropogenic-induced changes to the coastal ocean are increasing and will continue to do so as coastal regions are developed worldwide [Hallegraeff, 1993]. This is significant as the coastal ocean represents a significant fraction of the total ocean productivity [Field et al., 1998 and Ziemann, 1992], produces $90 \%$ of the global fish catch [Holligan and Reiners, 1992], and acts as a nutrient buffer between terrestrial ecosystems and the open ocean [Biscaye et al., 1994; Falkowski et al., 1994]. Despite the functional importance of the coastal ocean, our understanding of physical and biological processes in nearshore coastal 
waters $(<30 \mathrm{~m}$ deep) is severely limited due to its turbulent nature [Brink, 1997]. Therefore there is a need to develop effective means to map biological and chemical processes in coastal ecosystems.

Optical techniques are more commonly being used to assess spatial and temporal phytoplankton dynamics of offshore waters [cf. Advances in Ocean Optics, Journal of Geophysical Research, 100(C7), 13,133-13,372, 1995]; however, these approaches are often compromised because of the optical complexity of coastal waters. For example, ocean color satellite chlorophyll algorithms are based on ratios of remote sensing reflectance (Rrs) at different wavelengths. Most satellite algorithms are based on case 1 waters where the in situ absorption and water-leaving radiance (Lw) signal in the blue wavelengths are dominated by chlorophyll absorption while Lw in the green wavelengths is relatively insensitive to chlorophyll concentrations [Gordon and Morel, 1983]. Inaccuracies in this approach arise in coastal waters that contain significant amounts of other absorbing/ scattering compounds such as dissolved organics, detritus, and even variable phytoplankton communities [Morel and Prieur, 1977; Bergmann et al., 2004]. These errors directly impact the utility of optical techniques for estimating primary production and in turn impacts our understanding of carbon flux and nutrient recycling in nearshore ecosystems and their relation to ecosystem function [Jickells, 1998; Cloern, 2001].

Resolving the impact of primary production on any oceanic system is ultimately a question of scale [Bidigare et al., 1992], which has been recently addressed with comparisons of local, regional, and global productivity models in ocean observatories. Comparisons of modeled and measured primary production in these observatories showed mixed results. For example, satellite-based depth-integrated models [see Behrenfeld and Falkowski, 1997 for review] performed well when integrated over long time periods ( $>200$ days) but failed to resolve episodic production events on the order of days to months [Siegel et al., 2001]. Failures in these satellite approaches on regional scales are probably related to the degree to which particular algorithms are "tuned" to a specific region and the resolution of the time step in which satellites sample regions because of orbital trajectories and the occurrence of cloudy weather. Ondrusek et al. [2001] also reported that satellite-based depth-integrated models also did not perform well; however, estimates were improved using a wavelength-resolved model. This model was dependent on chlorophyll specific mean spectrally weighted absorption of phytoplankton ( $\left.\bar{a}^{*} \mathrm{ph}\right)$, 
which explained $82 \%$ of the variance and was able to resolve small-timescale phytoplankton blooms. Productivity models that incorporate $\bar{a}^{*}$ ph performed well in many different waters $\bar{a}^{*}$ ph [Smith et al., 1989; Bidigare et al., 1992; Waters et al., 1994; Morel et al., 1996] because they describe the fraction of photosynthetically available radiation (PAR) that is absorbed, which is a function of phytoplankton abundance, distribution, community structure, and physiology. Most often studies using these models use chemical extraction [Kishino et al., 1985] or highperformance liquid chromatography (HPLC) to measure $\bar{a}^{*}$ ph, which limits the amount of data that is available thus making comparisons to satellite data difficult [Siegel et al., 2001]. Secondarily, the presence of other compounds that absorb light in coastal waters can complicate these approaches.

Between the depth-integrated productivity models and the laboratory-dependent wavelength-resolved models there exists a gap in our ability to resolve and assess the episodic productivity events such as upwelling and river plumes in coastal systems that potentially account for a significant portion of the seasonal productivity signal [Walsh, 1978]. Depthintegrated approaches are limited not only in algorithm development but also in the resolution of temporal coverage due to clouds, while the use of wavelength resolved models derived from discrete water samples are limited to relatively short space and timescales because of sampling logistics. While there is progress being made in developing satellite productivity algorithms for coastal turbid waters, the issues of cloud cover persist. Therefore if we are to understand the episodic nature of coastal systems on seasonal scales, there is a need to collect parameters for wavelength-resolved models on high resolution space and timescales over broad regions to improve productivity estimates in turbid coastal regions.

Here we present a high-resolution time series of in-water physical and optical data collected by two cabled profilers as part of the Long-term Ecosystem Observatory (LEO) [see Schofield et al., 2002] to demonstrate an approach which can potentially "fill the gap" between satellite-based depth-integrated productivity models and productivity models dependent on discrete water samples such as wavelength-resolved models. From this time series we directly derive the spectral absorption of phytoplankton in coastal waters from bulk optical parameters measured with "off the shelf" technology and quantify its utility in bio-optically estimating primary productivity in coastal waters. We discuss assumptions and errors associated with our 
approach. These absorption-based bio-optical model estimates compared well with a physiologybased model rooted in measured photosynthetic-irradiance (P-E) parameters. This technique represents a high-resolution approach to calculating spectrally weighted phytoplankton absorption independent of laboratory extractions. While the scope of our study does not and cannot address the scope of the variability in primary production in the coastal ocean, we feel that automated optical approaches such as the one presented here provide a link for wavelengthresolved models to be applied on broad spatial scales through the use of autonomous platforms.

\section{Methods}

The 2000 Hyperspectral Coupled Ocean Dynamics Experiment (HyCODE) conducted at LEO represents an operational integrated coastal-ocean-observing network [Glenn et al., 2000; Schofield et al., 2002]. As part of this experiment, in-water physical and bio-optical time series data were collected from two profiling instrument nodes linked to shore via an electro-optical cable. These nodes were deployed approximately $4 \mathrm{~km}$ offshore in $13 \mathrm{~m}$ of water at $39-27.410 \mathrm{~N}$, 74-14.750W (node B and the optical profiler, Figure 1). This study represents data collected from calendar days 202-215. Node B provided hydrographic data, and the optical profiler provided optical data. These nodes were separated by about $100 \mathrm{~m}$.

\section{Profiler Data Sets}

As opposed to traditional methods of water-column profiling using lowered instrument packages from ships, both the optical profiler and node B had frames anchored to the seafloor with instrument packages attached to floating drogues that were depth controlled by an underwater winch. Data measured by these profilers streamed directly to the Rutgers University Marine Field Station (RUMFS) in real time via an electro-optical cable, where it was processed and visualized. Node B included a Sea-Bird conductivity-temperature-depth (CTD) mounted with a WET Labs chlorophyll fluorometer, which was sampled at $2 \mathrm{~Hz}$ and was profiled at a vertical rate of $2 \mathrm{~cm} \mathrm{~s}^{-1}$ at regular intervals. The optical profiler included a WET Labs ninewavelength absorption/attenuation meter (ac-9) (412,440, 488, 510, 532, 555, 650, 676, and 715 $\mathrm{nm}$ ), which sampled at $8 \mathrm{~Hz}$, and a two-wavelength backscatter/fluorometer HOBI Labs HydroScat-2 $(470$ and $676 \mathrm{~nm}$ ) that sampled at $2 \mathrm{~Hz}$. The optical profiler also profiled at a rate of $2 \mathrm{~cm} \mathrm{~s}^{-1}$. The ac-9 was factory and clean-water calibrated prior to the experiment, and 
absorption values were corrected for scattering by subtracting absorption at $715 \mathrm{~nm}$. Absorption, attenuation, backscatter, and chlorophyll fluorescence data were averaged into $0.25-\mathrm{m}$ bins. Because of the abundance of gelatinous zooplankton in the water column and their impact on the data when in the ac-9 tubes, a data filter was applied to eliminate spikes of data of greater than $300 \%$ change in signal for any $0.25-\mathrm{m}$ bin. While this would eliminate the potential to document any microlayer [Dekshenieks et al., 2001], we believe that the highly turbulent nature of these waters would minimize their presence. These "spikes" were rare and represented less than $2 \%$ of the total data. Additionally, discrete measurements at the profiler were taken by ship over a series of days at the profilers and analyzed for chlorophyll concentration using high-performance liquid chromatography to validate the fluorometer measurements. Node B logged a total of 255 downward profiles while 565 downward profiles were logged from the optical profiler during this experiment. Both node B and optical profiler profiling times were evenly distributed over the course of the experiment, with two exceptions when node B required servicing for about 4 hours.

Absorption, attenuation, and backscatter data were used as input into a radiative transfer model (Hydrolight v. 4.2) to model the spectral scalar irradiance from 400 to $700 \mathrm{~nm}$. Hydrolight model runs applied [Pope and Fry, 1997] pure water absorption values. The Hydrolight model computed a new spectral scattering phase function when the backscatter to total scatter ratio changed by more than 0.005 . These model runs also incorporated wind velocity measurements from the RUMFS meteorological tower to estimate surface roughness. The sky spectral radiance distribution is calculated within Hydrolight via RADTRAN based on user-supplied date, time, location, and cloud cover. This modeled spectral irradiance was scaled to wavelength-integrated photosynthetically active radiation values measured at the RUMFS field station. The derived spectral diffuse attenuation coefficients from Hydrolight were then used to propagate the scaled spectral irradiance to all depths.

\section{Optical Inversion Model and Mean Spectral}

Phytoplankton Absorption

Binned absorption data collected by the ac-9 were inverted using the optical signature inversion (OSI) model [Schofield et al., 2004] to estimate the relative abundance weights of phytoplankton, colored dissolved organic matter (CDOM), and detritus. This was based on inverting the bulk ac-9 absorption using a series of spectral absorption curves that represent the 
major absorbing constituents in the water column. Phytoplankton curves represented the means of high-light- and low-light-adapted phytoplankton from three major phytoplankton taxa: chlorophylla-c-, chlorophylla-b-, and phycobilin-containing phytoplankton [Johnsen et al., 1994]. CDOM and detritus absorption curves were treated as idealized exponential functions with a variable amplitude and spectral exponential decay slope (Figure 2). The OSI model varied the amplitudes of all these curves, as well as the exponential slopes of the CDOM and detritus curves within the boundaries of known constraints to minimize the difference between the total modeled absorption (sum of all phytoplankton, CDOM, and detritus curves) and total absorption measured by the ac-9. The OSI model returns the estimated weights of each phytoplankton group, and CDOM and detritus, as well as the spectral exponential slopes (or decay) of CDOM and detritus. These weights are analogous to the amplitude or abundance of their respective absorbing constituent.

Spectral absorption of phytoplankton $\left(a_{p h}(\lambda, z, t) m^{-1}\right)$ was calculated by

$$
a_{p h}(\lambda, z, t)=\sum_{n=1}^{3} w_{n(p h)}(z, t) a_{n(p h)}(\lambda)
$$

where $\mathrm{n}$ is the phytoplankton group number, $w_{n(p h)}(\mathrm{z}, \mathrm{t})$ is the calibrated inverted scalar weight calculated by the OSI model of a specific group of phytoplankton $\left(\mathrm{m}^{-1}\right)$, which is not spectrally dependent, and $a_{n(p h)}(\lambda)$ is the relative absorption of the input spectra of specific group of phytoplankton at a given wavelength. OSI calibration data showed that the amplitude of the phytoplankton spectra was generally underestimated due to the package effect of natural populations compared to the laboratory cultures from which the input spectra are derived. Although there was an underestimation, this underestimation was well quantified so that a calibration factor of 1.393 was applied to the relative weights of phytoplankton derived by the OSI [Schofield et al., 2004]. Modeled spectral scalar irradiance values were combined with $a_{p h}(\lambda, z, t)$ to calculate the mean spectral absorption of phytoplankton $a_{p h}(\lambda, z, t) m^{-1}$ using:

$$
\bar{a}_{p h(z, t)}=\frac{\int_{400}^{700} E_{0}(\lambda, z, t) a_{p h}(\lambda, z, t) d \lambda}{\int_{400}^{700} E_{0}(\lambda, z, t) d \lambda}
$$


where $E_{0}(\lambda, z, t)$ is spectral scalar irradiance from 400 to $700 \mathrm{~nm}\left(\mathrm{~W} \mathrm{~m}^{-2}\right)$ modeled by Hydrolight v. 4.2 .

\section{Bio-Optical Modeling of Primary Production from an ac-9}

The bio-optical model used in this study to calculate primary production was

$$
P P(z, t)=\bar{a}_{p h}(z, t) \phi_{\max } E_{k(P A R)} \tanh \left(\frac{E_{k(P A R)}(z, t)}{E_{k(P A R)}}\right)
$$

where $\operatorname{PP}(\mathrm{z}, \mathrm{t})$ is primary production $\left(\mathrm{mg} \mathrm{C} \mathrm{m}^{-3} \mathrm{~h}^{-1}\right), \bar{a}_{p h}(z, t)$ is calculated from equation (2) and was based solely on the optical inversion of ac-9 data, $\phi_{\max }$ is the maximum quantum yield of carbon fixation (mol $\mathrm{C}$ mol photons absorbed $\left.{ }^{-1}\right), E_{k(P A R)}$ is the irradiant flux at which photosynthesis becomes light saturated ( $\mu$ mol photons $\left.\mathrm{m}^{-2} \mathrm{~s}^{-1}\right)$, and $E_{0(P A R)}(\mathrm{z}, \mathrm{t})$ is the PARintegrated scalar irradiant flux incident on the phytoplankton cells ( $\mu \mathrm{mol}$ photons $\mathrm{m}^{-2} \mathrm{~s}^{-1}$ ) modeled by Hydrolight v. 4.2. $E_{0(P A R)}(\mathrm{z}, \mathrm{t})$ was used for this calculation because phytoplankton absorb light from all directions. Because our in situ optical data set did not include measurements of $\Phi_{\max }$ and $E_{k(P A R)}$, we conducted a literature survey to determine a mean for these waters (Figure 3, see figure legend for references). The data in Figure 3 represent the mean and standard deviation of the water column measured in each study. The mean $\Phi_{\max }$ and $E_{k(P A R)}$ value used in this study were calculated from all the literature studies in temperate and tropical waters except from those labeled "Antarctic"' or "New Jersey Coastal Region (LEO)', in Figure 3. We did not include values of $\Phi_{\max }$ and $E_{k(P A R)}$ estimated by $14 \mathrm{C}$ incubations from the LEO site in this mean because we wished to keep the biooptical method of estimating primary productivity and the physiological method of estimating productivity as independent as possible. The mean values used for $\Phi_{\max }$ and $E_{k(P A R)}$ for this study were $0.025 \mathrm{~mol} \mathrm{C} \mathrm{mol} \mathrm{photons} \mathrm{absorbed}^{-1}$ and 124.85 $\mu \mathrm{mol}$ photons $\mathrm{m}^{-\mathrm{s}}$, respectively. In this manuscript, this productivity model will be simply referred to as the bio-optical model. 


\section{Productivity Measurements of Phytoplankton}

Discrete water samples were collected at the profilers with Nisken bottles from the R/V Walford on calendar days 203, 208, and 212 at both the surface and at a depth of $8 \mathrm{~m}$ (Table 1).

Table 1. Phytoplankton Physiological Parameters Measured During Experiment

$\begin{array}{lcc}\text { Day }(\text { Depth }) & P_{\max } \mathrm{mol} \mathrm{C} \mathrm{m}^{-3} \mathrm{~h}^{-1} & E_{k} \mu \mathrm{mol} \text { photons } \mathrm{m}^{-2} \mathrm{~s}^{-1} \\ 203 \text { (surface) } & 1.21 & 146.44 \\ 203(8 \mathrm{~m}) & 1.07 & 55.66 \\ 208(\text { surface }) & 1.38 & 62.08 \\ 208(8 \mathrm{~m}) & 3.05 & 140.88 \\ 212(\text { surface }) & 1.76 & 96.09 \\ 212(8 \mathrm{~m}) & 3.64 & 71.23\end{array}$

These days coincided with major changes in water-column structure that were observed from real-time observation of profiler data, which allowed for adaptive sampling. These samples were collected at approximately $1000 \mathrm{LT}$ on these days and kept dark for 30 min while returning to the field station. Aliquots were then filtered onto $47-\mathrm{mm} \mathrm{GF} / \mathrm{F}$ filters and stored in an $-80^{\circ} \mathrm{C}$ freezer for phytoplankton pigment determination using HPLC analysis using the methods of Wright et al. [1991]. Photosynthetic irradiance curves were measured using the methods of Prézelin et al. [1989]. Measured carbon uptake values for each of the P-E curves were curve fitted as a hyperbolic tangent function using the Simplex method of Caceci and Cacheris [1984] to estimate the chlorophyll-specific maximum photosynthetic rate $\left(\mathrm{P}_{\max }, \mathrm{mol} \mathrm{C} \mathrm{m}^{-1} \mathrm{~h}^{-1}\right)$, the lightlimited slope of photosynthesis $(\alpha)$, and the photosynthetic light-saturation parameter $\left(E_{k(P A R)}\right)$. Error estimates were calculated using the methods of Zimmerman et al. [1987].

The general model used in this study to calculate physiology-based primary production is based on the work of Jassby and Platt [1976]:

$$
P P(z, t)=P_{\text {max }}(z, t) \tanh \frac{E_{0(P A R)}(z, t)}{E_{k(P A R)}(z, t)}
$$


where PP, $\mathrm{P}_{\max }, E_{0(P A R)}$, and $E_{k(P A R)}$ are as described previously. To extrapolate physiological parameters $\left(\mathrm{P}_{\max }\right.$ and $\left.E_{k(P A R)}\right)$ measured at the profiler over the same depth-time area that the profilers were deployed (give them similar $\mathrm{z}$ and $\mathrm{t}$ distribution as equation (3)), multivariate cluster analysis of paired salinity and temperature observations from node B was used to define statistical boundaries on water masses. Salinity and temperature values were standardized by subtracting the mean of the data set and dividing by the standard deviation of the data set. On the basis of Euclidian distance, a distance matrix was calculated for the data set and then hierarchically clustered according to Ward's linkage [Ward, 1963]. The generated similarity index was used in conjunction with a multivariate analysis of variance (MANOVA) to define the major groupings of temperature and salinity observations (i.e., water masses). Physiological parameters were measured within each of the statistically distinct water masses except a water mass in the lower portion of the water column on days 213-215. This restricted physiologybased depth-integrated productivity calculations to days 202-212. In the case where a specific water mass was continuous throughout the depth of the water column, the water mass was subdivided at the 8-m mark, below the climatological depth of the thermocline in this area $(7 \mathrm{~m})$, so that the physiological parameters measured at the surface and at 8-m depth in the water mass were separated. On the basis of this extrapolation method, the depth-integrated productivity was calculated.

The assumptions of this approach do not incorporate diel variation of physiological parameters, which have been shown to be important in calculating short-timescale productivity [Sournia, 1974; Prézelin et al., 1987; Prézelin, 1991]. To mediate these effects, measurements were made at approximately the same time of day. However, these diel cycles introduce errors into our comparison of physiology-based and bio-optical calculations of primary production, although not just our errors. In this manuscript, this productivity model will be referred to as the physiology-based model. 


\section{Results}

\section{Hydrographic and Optical Variability at the LEO Profilers}

The winds, surface currents, and hydrographic structure of the water column were highly variable with several major events occurring during the experiment (Figures 4 and 5). These events directly impacted the distribution of phytoplankton biomass and other absorbing constituents such as CDOM and detritus that modulate the in-water spectral light field, therefore affecting what phytoplankton can absorb for photosynthesis. On calendar days 202-203, strong northeasterly winds were in phase with the surface currents, measured using a SeaSonde Radar system, showing a strong southward alongshore flow (Figure 4). The density structure was stratified during this time period (Figure 5a). On days 203-205, the winds shift abruptly, blowing from the southwest, and surface currents progressively rotated toward the northeast. This is coincident with the appearance of comparatively denser water at the bottom, which resulted in strong stratification. The presence of this cold bottom water was reflected in the optical properties. Associated with the bottom water were smaller particles as indicated by the backscatter to total scatter ratio (Figure 5b) [Stramski and Morel, 1990]. During these times of strong stratification the majority of the phytoplankton biomass was present in the upper water column (Figures 5c and 5d). The exponential slopes and relative abundance of the CDOM and detritus also reflected the physical hydrography with low concentrations and large exponential slopes associated with the dense bottom water (Figure 6 and Table 2). Large exponential slopes are often associated with marine-derived waters in this region, reflecting the degradation and breaking of double bonds of the CDOM [Vodacek et al., 1997].

On day 206, winds became northeasterly, and the surface currents turned to the southwest; however, the bottom water intrusion of dense seawater persisted until day 207 when it was eventually dissipated during a period of strong winds and increasing current velocities. When the stratification eroded, phytoplankton concentrations increased throughout the water column (Figures 5c and 5d). Interestingly, the concentration of the CDOM and detritus decreased dramatically throughout the water column during these mixing events (Figures $6 \mathrm{a}$ and 6c). The northeasterly winds persisted until approximately day 208. Despite this, surface currents continued to flow southward with increasing velocity. This trend continued until day 210 , when winds were from the north, and surface currents were flowing $>60 \mathrm{~cm} \mathrm{~s}^{-1}$ to the south. The entire 
water column during this time was well mixed, with decreased density and salinities as low as 28.5 practical salinity unit (Figure 5a).

Cross-shore transects of salinity and temperature to the north of the profiler and measured currents surface current radars (Figure 4) indicated a large volume of southward flowing lowsalinity water. Given the large volume of relatively fresh water at the profilers, the water was likely from the Hudson River [Johnson et al., 2003; R. J. Chant and S. M. Glenn, Secondary circulation and mixing in a buoyant coastal current, submitted to Journal of Geophysical Research, 2003, hereinafter referred to as Chant and Glenn, submitted manuscript, 2003]. The presence of the Hudson River water was clearly delineated in the optical properties reflecting high concentrations of large particles (Figure 5b), phytoplankton (Figures 5c and 5d), CDOM, and detritus (Figures 6a and 6c). The phytoplankton community during this experiment was primarily diatom based determined by the abundance of fucoxanthin in the HPLC samples. Concurrent with the high concentrations of CDOM and detritus was a decrease in their respective spectral exponential slopes. Low exponential slopes often indicate that the CDOM and detrital material are young. Local winds did not heavily influence the plume (Chant and Glenn, submitted manuscript, 2003) suggesting southward flow resulted from a buoyancy-derived pressure gradient. Alternating southeast and southwest winds blew from days 211 to 215 while the surface currents weakened and eventually the currents veered offshore (Figure 4). Associated with this was a restratification and intrusion of dense bottom waters. As before, the dense bottom waters were characterized by low concentrations of phytoplankton, CDOM, detritus, and small particles (Figures 5 and 6).

The clustering scheme applied to the hydrographic data suggests that at least three water masses were advected past and sampled by the profilers. A MANOVA showed that the three water masses defined by this clustering scheme were significantly different (Pillai Trace approximately $\mathrm{F}=2988.747, \mathrm{p}=0.000$ ). The major features defined by cluster analysis as specific water mass types were the deep intrusions on calendar days 202-207 and 212-215, intermediate mixed regime on calendar days 206-210, and the Hudson River Plume on calendar days 210-214 (Figure 5a). This clustering was also consistent with the major changes observed in the in situ optical properties and derived optical constituents (Figures 5 and 6). While the time series shown has multiple forcing events, in general, as the water column becomes less dense, absorption and attenuation increased as well as the derived loads of phytoplankton biomass, 
CDOM, and detritus. This suggests that the high optical loads during this time period may be terrestrial in origin. Conversely, the particle size index (ratio of backscatter to total scatter), and the spectral exponential slopes of CDOM and detritus were positively correlated. This suggests that steeper slopes and smaller particles are coincident with marine waters during this time period (Table 2).

Table 2. Correlation of Inherent and Derived Optical Properties with Density

$\begin{array}{llc}\text { Variable } & \mathrm{R}^{2} & \text { Slop } \\ A_{(488)}, m^{-1} & 0.58 & - \\ C_{(488)}, m^{-1} & 0.27 & + \\ B_{b(470)}, m^{-1} & 0.06 & + \\ B_{b(470)}, B_{b(488)} & 0.27 & - \\ \text { Chlorophyll fluorescence } & 0.22 & - \\ W_{\text {phyto }} & 0.46 & - \\ W_{\text {CDOM }} & 0.59 & - \\ W_{\text {detritus }} & 0.60 & + \\ S_{\text {CDOM }} & 0.03 & + \\ S_{\text {detritus }} & 0.02 & \end{array}$

\section{Spectrally Weighted Phytoplankton Absorption}

Surface irradiance during the course of the experiment was highly variable due to passing storms and patchy cloud cover. Peak $E_{d(P A R)}$ values during the clearest atmospheric days approached $2000 \mu \mathrm{mol}$ photons $\mathrm{m}^{-2} \mathrm{~s}^{-1}$ while surface irradiance values during stormy days were four times lower (Figure 7a). In general, PAR attenuated rapidly, with its first attenuation length usually $0.5-1.5 \mathrm{~m}$ deep (Figure $7 \mathrm{c}$ ). Modeled hyperspectral profiles of $E_{0}(\lambda)$ indicated that attenuation was largest in the wavelengths associated with maximal absorption peaks of chlorophyll, illustrating the importance of phytoplankton to bulk optical properties. Similar to chlorophyll biomass, values of $\bar{a}_{p h}$ calculated from equation (2) showed the largest values in the Hudson River water mass and the lowest values in the deep water intrusions. However, $\bar{a}_{p h}$ 
decreased and smeared with depth due to the decreased availability of red and blue wavelengths of light at depth. The $\bar{a}_{p h}$ thus did not reflect the same vertical and temporal structure as chlorophyll fluorescence because the wavelengths at which chlorophyll absorbs maximally were differentially attenuated more rapidly in the water column due to the spectral optical structure of the water column (Figures $7 \mathrm{~b}$ and $7 \mathrm{~d}$ ).

\section{Physiology and ac-9-Derived Bio-0ptically Based Primary Production}

To extrapolate discrete $14 \mathrm{C}$ measurements over time, measured physiological variables associated with $14 \mathrm{C}$ incubations were assigned to specific water masses defined by multivariate cluster analysis of temperature and salinity as described in section 2.4. These physiological measurements extrapolated into depth and time space using water mass analysis were then combined with the continuous light fields based on the in situ optical profiler measurements and the Hydrolight calculations (Figure 7c). Values were integrated over depth and will be herein referred to as the productivity calculated through the physiology based model. This time series of depth-integrated primary production was compared to the bio-optical model estimates using the ac-9-derived weighted phytoplankton absorption and equation (3).

To convert $\bar{a}_{p h}$ into a productivity rate, we required estimates of $\Phi$ max and $E_{k(P A R)}$ which were taken from the literature (Figure 3). Using the mean values for Фmax $(0.025$ mol C mol photons $\left.{ }^{-1}\right)$ and $E_{k(P A R)}\left(124.85 \mu \mathrm{mol}\right.$ photons $\left.\mathrm{m}^{-2} \mathrm{~s}^{-1}\right)$ for temperate marine waters, the depth-integrated bio-optical model showed good agreement with depth-integrated physiology-based model (r $2=0.91, \mathrm{p}<0.001$ ) (Figure 8). Assuming a constant Фmax and $E_{k(P A R)}$ values is known to be problematic, so we conducted a sensitivity analysis over the range of $\Phi_{\max }$ and $E_{k(P A R)}$ observed in the world's oceans. The sensitivity analysis is presented as isoclines in Figure 9. The isoclines represent the average percent difference between the physiology and bio-optical-modeled productivity in our study. These differences were calculated for three timescales, and all showed the general inverse relationship between Фmax and $E_{k(P A R)}$. The purpose of time-integrating water-column productivity over these three scales is that they address the short- to medium-timescale events which characterize physical forcing and biological responses in the LEO-15 research area (S. M. Glenn et al., Studying the biogeochemical impact of summertime upwelling using a coastal ocean observatory, submitted to Journal of Geophysical Research, 2003, hereinafter referred to as Glenn et al., submitted 
manuscript, 2003). Interestingly, the mean-paired $\Phi \max$ and $E_{k(P A R)}$ observations from our literature survey (Figure 3) were generally coincident with the error minima (Figure 9).

\section{Discussion}

\section{Physical and Optical Properties of the Study Site}

Southwesterly wind-driven coastal upwelling is an annual event at LEO and has been observed every summer over the last decade (Glenn et al., submitted manuscript, 2003). These upwelling-favorable events result in phytoplankton blooms [Schofield et al., 2002] and represent one of the dominant biogeochemical signals in nearshore ( $<30 \mathrm{~m}$ depth) New Jersey coastal waters (Glenn et al., submitted manuscript, 2003). However, the optical properties in the region are complex due to the proximity of the Mullica River estuary (Figure 1) and the presence of coastally trapped freshwater plumes from the Hudson River, which introduce significant amounts of CDOM and detritus. Therefore the waters at LEO are often classified as "case 2" [Morel and Prieur, 1977]. The T-S relationships in this study indicated the presence of significantly different water masses; however, their boundaries were difficult to resolve from a T-S diagram alone. Measured and derived optical properties were also highly variable and showed significant correlations to hydrographic structure (Table 2).

\section{Bio-Optical Modeling of Photosynthesis in Coastal Waters}

Implicit in many primary production models is some parameterization of $\bar{a}_{p h}$ [cf. Bidigare et al., 1992], which has traditionally been measured using discrete water samples or estimated empirically [Bricaud et al., 1995; Cleveland, 1995]. Often $\bar{a}_{p h}$ is derived from the product of biomass and biomass-normalized phytoplankton absorption $a_{p h}^{*}$ [Sakshaug et al., 1997]. The utility of this approach is limited given the laboratory requirements for deriving $a_{p h}^{*}$ and the well-documented variability in $a_{p h}^{*}$ seasonally [Sathyendranath et al., 1999], regionally [Bricaud and Stramski, 1990; Hoepffner and Sathyendranath, 1992; Sosik, 1996; Arbones et al., 2000], and physiologically [Prézelin and Boczar, 1986; Lewis et al., 1988; Bricaud et al., 1995]. Ideally, the parameterization of $a_{p h}^{*}$ is not needed aph if $\bar{a}_{p h}$ could easily be derived from in situ bulk optical measurements. Currently, off-the-shelf technology offers the potential to measure bulk optical properties [Dickey, 1991; Chang and Dickey, 1999]. 
High-resolution maps of $\bar{a}_{p h}$ can be derived from an ac-9 (Figure 7d) allowing wavelength dependency of phytoplankton absorption and spectral light quality to be estimated. To first order $\bar{a}_{p h}$ is described by chlorophyll biomass $\left(\mathrm{r}^{2}=0.71, \mathrm{p}=0.000\right)$; however, $\bar{a}_{p h}$ is a consistently decreasing function with depth. This decrease, a second-order effect, reflects the spectral skewing of light with depth. This spectral skewing of $\bar{a}_{p h}$ was sensitive to the relative concentrations of the other in-water constituents. For example, when CDOM and detritus signals were large (day 210) blue wavelengths (400-450 $\mathrm{nm}$ ) of light were attenuated $30 \%$ faster than when CDOM and detritus signals were low (day 202). In contrast, the difference in red wavelength (650-700 nm) attenuation was approximately $7 \%$. The result of this variable skewing of the in situ light field accounts for the scatter between the phytoplankton fluorescence estimates and $\bar{a}_{p h}$. Given in situ $\bar{a}_{p h}$ and $E_{0(P A R)}$, the remaining difficulty for estimating photosynthesis is defining the magnitude of $\Phi_{\max }$ and $E_{k(P A R)}$ as these terms cannot currently be derived optically. While $\Phi_{\max }$ has been related to fluorescence transients via fast repetition rate fluorometry [Kolber et al., 1988; Falkowski, 1992; Kolber and Falkowski, 1993], conversion of the electrons generated by photosystem II to carbon fixation is difficult [Kroon and Dijkman, 1996]. This conversion requires a thorough understanding of the environmental and physiological regulation of the photosynthetic quotient [Laws, 1991]. In nature, both $\Phi_{\max }$ and $E_{k(P A R)}$ are variable in time and space ranging from hours to seasons [Sournia, 1974; Prézelin, 1991; Kyewalyanga et al., 1998; Gong et al., 1999; Sathyendranath et al., 1999; Marra et al., 2000] and meters to kilometers [Schofield et al., 1993; Lindley et al., 1995; Sosik, 1996; Kyewalyanga et al., 1998]. Over these scales, $\Phi_{\max }$ and $E_{k(P A R)}$ can vary by a factor of 10 and 5, respectively. To compensate for this effect, $E_{k(P A R)}$ has been empirically or theoretically parameterized from underwater irradiance fields [Waters et al., 1994; Moline et al., 1998]. Parameterizations of $\Phi_{\max }$ have proven difficult, and so is often assumed to be constant or is measured using radiolabel incubations [Marra, 1993; Waters et al., 1994; Ondrusek et al., 2001]. It was a pleasant surprise then that using temperate and tropical ocean means of $\Phi_{\max }$ and $E_{k(P A R)}$ from the literature resulted in such a good agreement of physiology-based productivity. Therefore we felt this serendipitous result merited further analysis.

The relationship between $\bar{a}_{p h}, E_{k(P A R)}$, and $\Phi$ max is coupled via 


$$
E_{k(P A R)}=\frac{P_{\max }}{\Phi_{\max } \bar{a}_{p h}}
$$

which implies a general inverse, covariant relationship between the product of $\Phi_{\max }$ and $\bar{a}_{p h}$, and $E_{k(P A R)}$. However, sensitivity analyses of these terms in bio-optical productivity models [Sosik, 1996 ] suggest that $\bar{a}_{p h}$ is not strongly coupled to either $E_{k(P A R)}$ or $\Phi_{\max }$. This effect is probably a function of photoprotective pigments [Bidigare et al., 1989; Schofield et al., 1996]. In contrast, $E_{k(P A R)}$ and $\Phi_{\max }$ appear to be strongly coupled with each other [see Figure 6 in the work of Sosik, 1996]. This is supported by the non-normal natural distribution of $\Phi_{\max }$ and $\left.E_{k(P A R)}\right)$ which shows an inverse distribution suggesting that $\Phi_{\max }$ and $E_{k(P A R)}$ covary in a nonlinear fashion (Figures 3 and 9). This implies that their errors are not additive. Therefore determining the sensitivity of an absorption-based bio-optical model without considering this covariance would overestimate the importance of the variability of $\Phi_{\max }$ and $E_{k(P A R)}$ to a productivity estimate. Because of this we varied $\Phi_{\max }$ and $E_{k(P A R)}$ over their natural ranges independent of other water-column properties to quantify their impact on water-column productivity. In addition, this error analysis assumed that errors in the model related to the production of photoprotective pigments were low because they were found in negligible amounts in the HPLC analysis (zeaxanthin $0.1-0.2 \mathrm{mg} \mathrm{L}^{-1}$ ) during the experiment and because of the highly turbid nature of the water column.

The net result of this analysis is that the variation in $\Phi_{\max }$ dominates the error in the productivity estimates over hourly, daily, and 11-day timescales in temperate waters (Figure 9). This is not surprising given past field results in which $\Phi_{\max }$ varied by a factor of 10 [Bannister and Weidemann, 1984; Cleveland et al., 1989; Schofield et al., 1993; Babin et al., 1996]. While the bio-optical model was very sensitive to $\Phi_{\max }$, when considering literature values, the variability in $\Phi_{\max }$ is remarkably constrained temperate and tropical waters ranging from -0.015 to $0.04 \mathrm{~mol} \mathrm{C} \mathrm{mol} \mathrm{photons} \mathrm{absorbed}{ }^{-1}$. Generally, the highest values are found at depth, often near nutriclines [Cleveland et al., 1989], where photosynthesis is light limited. Therefore the impact on integrated water-column productivity is relatively small. In these

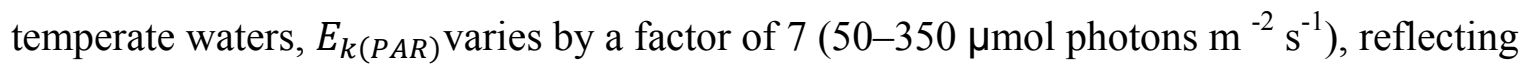
photoacclimation processes [Falkowski and LaRoche, 1991; Escoubas et al., 1995]. However, 
the impact of $E_{k(P A R)}$ variability is relatively small in our analysis, as is evidenced by the elongation of the error contours along the $E_{k(P A R)}$ axis (Figure 9). This reflects that a change in $E_{k(P A R)}$ (especially when $\left.E_{k(P A R)}>100\right)$ does not dramatically impact the proportion of the total water-column photosynthesis that is light-saturated as this is largely determined by the exponential decay of light. It is the combined effect of naturally constrained $\Phi_{\max }$ values and the rapid exponential decay of light in our system that allow for our approach of bio-optically estimating productivity to reasonably approximate the physiology-based model.

While these general paradigms apply to temperate and tropical waters, caution should be used, as this is not a global phenomenon. In the Southern Ocean, discrete and water-columnaveraged $\Phi_{\max }$ values (Figures 3 and 9) are on average two times higher than that measured in tropical and temperate waters. The variance in $\Phi_{\max }$ is also high. In these polar waters the $E_{k(P A R)}$ magnitude $\left(<100 \mu\right.$ mol photons, $\left.\mathrm{m}^{-2} \mathrm{~s}^{-1}\right)$ and variability (factor of $4)$ is low. Given equation (3) and that mean and variability of $E_{k(P A R)}$ are relatively low, the lightsaturated photosynthetic term is dominated by the product of $\Phi_{\max }$ and $\bar{a}_{p h}$.

In contrast, the tropical and temperate oceans are generally stratified much of the year and have high-incident irradiance during the phytoplankton growing season. Because of these factors, the euphotic zone is generally nutrient limited. The combination of low nutrient with high-light conditions can reduce the average water column, $\Phi_{\max }$. This decrease reflects the production of photoprotective pigments [Bidigare et al., 1989; Schofield et al., 1996; Fujita et al., 1994; Babin et al., 1996] and a decrease in functional photosynthetic reaction centers [Falkowski et al., 1989]. The phytoplankton response to the high-light environment is an increase in $E_{k(P A R)}$ given a sufficiently stable environment [Ryther and Menzel, 1959; Co`te` and Platt, 1983].

\section{Conclusions}

Bio-optical measurements show promise for mapping phytoplankton; however, these techniques have often been compromised in turbid coastal waters. The bulk and derived optical parameters mimicked the hydrographic structure that was dominated by three distinct water masses advected through the study area. The correlations of density with bulk/derived optical properties suggest that much of the optical load is from terrestrial sources. Calculated $\bar{a}_{p h}$, from the relative phytoplankton weight and spectral irradiance showed that $\bar{a}_{p h}$ was to first order a 
function of biomass but was modulated based on the spectral absorbing characteristics of inwater biotic and nonbiotic constituents. In addition, $\bar{a}_{p h}$ could be used to initialize a bio-optical productivity model and calculate productivity within $20 \%$ given reasonable estimates of $\Phi_{\max }$ and $E_{k(P A R)}$. Sensitivity analysis of the bio-optical model indicated that most of the error is potentially associated with $\Phi_{\max }$; however, the natural range of water-column-averaged $\Phi_{\max }$ is constrained. The bio-optical model was not as sensitive to $E_{k(P A R)}$ when estimating water-column productivity because of the exponential decay of light in these turbid waters.

\section{Acknowledgments.}

Special thanks to two anonymous reviewers whose comments significantly improved the flow and content of this manuscript. Thanks and cold beer owed to Mike Crowley, Josh Kohut, Erica Heine, Mike Purcell, Christy Herren, Amanda Ashe, Dwight Peterson, Grace Chang, Sage Lichtenwalner, and Alan Weidmann. Support was provided by the Office of Naval Research's COMOP and HyCODE programs (N00014-97-0767, N0014-99-0196), and the National Ocean Partnership Program (N00014-97-1-1019).

\section{References}

Arbones, B., F. G. Figueiras, and R. Varela (2000), Action spectrum and maximum quantum yield of carbon fixation in natural phytoplankton populations: Implications for primary production estimates in the ocean, J. Mar. Syst., 26, $97-114$.

Babin, M., A. Morel, H. Claustre, A. Bricaud, Z. Kolber, and P. G. Falkowski (1996), Nitrogen-and irradiance-dependent variations of the maximum quantum yield of carbon fixation in eutrophic, mesotrophic, and oligotrophic marine systems, Deep Sea Res., Part I, 43(8), 1241-1272.

Bannister, T. T., and A. D. Weidemann (1984), The maximum quantum yield of phytoplankton photosynthesis in situ, J. Plankton Res., 6(2), 275-294.

Behrenfeld, M. J., and P. G. Falkowski (1997), A consumer's guide to phytoplankton productivity models, Limnol. Oceanogr., 42(7), 1479 - 1491.

Bergmann, T., G. Fahnenstiel, S. Lohrenz, D. Millie, and O. Schofield (2004), Impacts of a recurrent resuspension event and variable phytoplankton community composition on remote sensing reflectance, J. Geophys. Res., 109, C10S15, doi:10.1029/2002JC001575.

Bidigare, R. R., O. Schofield, and B. B. Prézelin (1989), Influence of zeaxanthin on quantum yield of photosynthesis of Synechococcus clone WH7803 (DC2), Mar. Ecol. Prog. Ser., 56, 177 - 188.

Bidigare, R. R., B. B. Prézelin, and R. C. Smith (1992), Bio-optical models and the problems of scaling, in Primary Productivity and Biogeochemical Cycles in the Sea, Environ. Sci. Res., vol. 43, edited by P. G. Falkowski, pp. 175 - 212, Plenum, New York. 
Bienfang, P. K., and D. A. Ziemann (1992), The role of coastal high latitude ecosystems in global export production, in Primary Productivity and Biogeochemical Cycles in the Sea, Environ. Sci. Res., vol. 43, edited by P. G. Falkowski, pp. 285 - 297, Plenum, New York.

Biscaye, P. E., C. N. Flagg, and P. G. Falkowski (1994), The shelf edge exchange experiment, Seep, II, An introduction to hypotheses, results and conclusions, Deep Sea Res., Part II, 41(2), 231 - 253.

Bricaud, A., and D. Stramski (1990), Spectral absorption coefficients of living phytoplankton and nonalgal biogenous matter: A comparison between the Peru upwelling area and the Sargasso Sea, Limnol. Oceanogr., 35(3), $562-582$.

Bricaud, A., M. Babin, A. Morel, and H. Claustre (1995), Variability in the chlorophyll-specific absorption coefficients of natural phytoplankton: Analysis and parameterization, J. Geophys. Res., 100(C7), 13,321-13,332.

Brink, K. H. (1997), Observational coastal oceanography, paper presented at National Science Foundation OCE Workshops, Monterey Bay, Calif. Caceci, M. S., and W. P. Cacheris (1984), Fitting curves to data, Byte, 9, $340-362$.

Chang, G. C., and T. D. Dickey (1999), Partitioning in situ spectral absorption by use of moored spectral absorption-attenuation meters, Appl. Opt., 38(15), 3876-3887.

Cleveland, J. S. (1995), Regional models for phytoplankton absorption as a function of chlorophyll a concentration, J. Geophys. Res., 100(C7), 13,333-13,344.

Cleveland, J. S., M. J. Perry, D. A. Kiefer, and M. C. Talbot (1989), Maximal quantum yield of photosynthesis in the northwestern Sargasso Sea, J. Mar. Res., 47, $869-886$.

Cloern, J. E. (2001), Our evolving conceptual model of the coastal eutrophication problem, Mar. Ecol. Prog. Ser., 210, $223-253$.

Co`te', B., and T. Platt (1983), Day-to-day variations in the spring-summer photosynthetic parameters of coastal marine phytoplankton, Limnol. Oceanogr., 28(2), 320 -344.

Dekshenieks, M. M., P. L. Donaghay, J. M. Sullivan, J. E. B. Rines, T. R. Osborn, and M. S. Twardowski (2001), Temporal and spatial occurrence of thin phytoplankton layers in relation to physical processes, Mar. Ecol. Prog. Ser., 223, $61-71$.

Dickey, T. D. (1991), The emergence of concurrent high-resolution physical and bio-optical measurements in the upper ocean and their applications, Rev. Geophys., 29(3), $383-413$. 
Escoubas, J. M., M. Lomas, J. LaRoche, and P. G. Falkowski (1995), Light intensity regulation of cab gene transcription is signaled by the redox state of the plastoquinone pool, Proc. Natl. Acad. Sci. U. S. A., $92,10,237-10,241$.

Falkowski, P. G. (1992), Molecular ecology of phytoplankton photosynthesis, in Primary Productivity and Biogeochemical Cycles in the Sea, edited by P. G. Falkowski, pp. 47 -67, Plenum, New York.

Falkowski, P. G., and J. LaRoche (1991), Acclimation to spectral irradiance in algae, J. Phycol., 27, 8 14.

Falkowski, P. G., A. Sukenik, and R. Herzig (1989), Nitrogen limitation in Isochrysis galbana (Haptophyceae), II, Relative abundance of chloroplast proteins, J. Phycol., 25, 471 - 478.

Falkowski, P. G., P. E. Biscaye, and C. Sancetta (1994), The lateral flux of biogenic particles from the eastern North American continental margin to the North Atlantic Ocean, Deep Sea Res., Part II, 41(2), $583-602$.

Field, C. B., M. J. Behrenfeld, J. T. Randerson, and P. Falkowski (1998), Primary production of the biosphere: Integrating terrestrial and oceanic components, Science, 281, 237 -240.

Figueiras, F. G., B. Arbones, and M. Estrada (1999), Implications of biooptical modeling of phytoplankton photosynthesis in Antarctic waters: Further evidence of no light limitation in the Bransfield Strait, Limnol. Oceanogr., 44(7), 1599 - 1608.

Fujita, Y., A. Murakami, K. Aizawa, and K. Ohki (1994), Short-term and long-term adaptation of the photosynthetic apparatus: Homeostatic properties of thylakoids, in The Molecular Biology of Cyanobacteria, edited by D. A. Bryant, pp. 677 - 692, Kluwer Acad., Norwell, Mass.

Glenn, S. M., M. F. Crowley, D. B. Haidvogel, and Y. T. Song (1996), Underwater observatory captures coastal upwelling events off New Jersey, Eos Trans. AGU, 77, 233, 236.

Glenn, S. M., T. D. Dickey, W. P. Bisset, and O. Schofield (2000), Long-term real-time coastal ocean observation networks, Oceanography, 13, $24-34$.

Gong, G., J. Chang, and Y. Wen (1999), Estimation of primary production in the Kuroshio waters northeast of Taiwan using a photosynthetic irradiance model, Deep Sea Res., Part I, 46, 93 -108. Gordon, H. R., and A. Morel (1983), Remote Sensing of Ocean Color for Interpretation of Satellite Visible Imagery: A Review, Springer-Verlag, New York.

Hallegraeff, G. M. (1993), A review of harmful algal blooms and their apparent global increase, Phycology, 32, $79-99$. 
Hoepffner, N., and S. Sathyendranath (1992), Bio-optical characteristics of coastal waters: Absorption spectra of phytoplankton and pigment distribution in the western North Atlantic, Limnol. Oceanogr., $37(8), 1660-1679$.

Holligan, P. M., and W. A. Reiners (1992), Predicting the responses of the coastal zone to global change, Adv. Ecol. Res., 22, $211-221$.

Jassby, A. D., and T. Platt (1976), Mathematical formulation of the relationship between photosynthesis and light for phytoplankton, Limnol. Oceanogr., 21, 540 - 547.

Jickells, J. D. (1998), Nutrient biogeochemistry of the coastal zone, Science, 281, 217 - 222.

Johnsen, G., O. Samset, L. Granskog, and E. Sakshaug (1994), In vivo absorption characteristics in 10 classes of bloom-forming phytoplankton: Taxonomic characteristics and responses to photoadaptation by means to discriminant and HPLC analysis, Mar. Ecol. Prog. Ser., 105, 149 - 157.

Johnson, D. R., J. Miller, and O. Schofield (2003), Dynamics and optics of the Hudson River outflow plume, J. Geophys. Res., 108(C10), 3323, doi:10.1029/2002JC001485.

Kishino, M., M. Takahashi, N. Okami, and S. Ichimura (1985), Estimation of the spectral absorption coefficients of phytoplankton in the sea, Bull. Mar. Sci., 37(2), 634- 642.

Kolber, Z. S., and P. G. Falkowski (1993), Use of active fluorescence to estimate phytoplankton photosynthesis in situ, Limnol. Oceanogr., 38, 1646-1665.

Kolber, Z. S., J. Zehr, and P. G. Falkowski (1988), Effects of growth irradiance and nitrogen limitation on photosynthetic energy conversion in photosystem II, Plant Physiol., 88, 923-929.

Kroon, B. M. A., and N. A. Dijkman (1996), Photosystem II quantum yields, off-line measured P/I parameters and carbohydrate dynamics in Chlorella vulgaris grown under a fluctuating light regime and its application for optimizing mass cultures, J. Appl. Phycol., 8(4- 5), 313 - 323.

Kyewalyanga, M. N., T. Platt, S. Sathyendranath, V. A. Lutz, and V. Stuart (1998), Seasonal variations in physiological parameters of phytoplankton across the North Atlantic, J. Plankton Res., 20(1), 17 - 42.

Laws, E. A. (1991), Photosynthetic quotients, new production and net community production in the open ocean, Deep Sea Res., Part A, 38, $143-167$.

Lewis, M. R., O. Ulloa, and T. Platt (1988), Photosynthetic action, absorption, and quantum yield spectra for a natural population of Oscillatoria in the North Atlantic, Limnol. Oceanogr., 33(1), 92 - 98.

Lindley, S. T., R. R. Bidigare, and R. T. Barber (1995), Phytoplankton photosynthesis parameters along 140_W in the equatorial Pacific, Deep Sea Res., Part II, 42(2- 3), 441 - 463. 
Lorenzo, L. M., B. Arbones, F. G. Figueiras, G. H. Tilstone, and F. L. Figueroa (2002), Photosynthesis, primary production and phytoplankton growth rates in Gerlache and Bransfield Straits during Austral summer: Cruise of FRUELA 95, Deep Sea Res., Part II, 49, 707 - 721.

Marra, J. (1993), Proportionality between in situ carbon assimilation and bio-optical measures of primary production in the Gulf of Maine in summer, Limnol. Oceanogr., 38(1), 232 - 238.

Marra, J., C. C. Trees, R. R. Bidigare, and R. T. Barber (2000), Pigment absorption and quantum yields in the Arabian Sea, Deep Sea Res., Part II, 47, $1279-1299$.

Moline, M., and B. B. Prézelin (1996), Long-term monitoring and analysis of physical factors regulating variability in coastal Antarctic phytoplankton biomass, in situ productivity and taxonomic composition over subseasonal, seasonal and interannual time scales, Mar. Ecol. Prog. Ser., 145, 143 -160.

Moline, M. A., O. Schofield, and N. P. Boucher (1998), Photosynthetic parameters and empirical modeling of primary production: A case study on the Antarctic Peninsula shelf, Antarct. Sci., 10(1), 45 54.

Morel, A., and L. Prieur (1977), Analysis of variations in ocean color, Limnol. Oceanogr., 22, 709 - 722.

Morel, A., D. Antoine, M. Babin, and Y. Dandonneau (1996), Measured and modeled primary production in the northeast Atlantic (EUMELI JGOFS program): The impact of natural variations in photosynthetic parameters in model predictive skill, Deep Sea Res., Part II, 43, $1273-1304$.

Ondrusek, M. E., R. R. Bigidare, K. Waters, and D. M. Karl (2001), A predictive model for estimating rates of primary production in the subtropical North Pacific Ocean, Deep Sea Res., Part II, 48, 1837 1863.

Pope, R., and E. Fry (1997), Absorption spectrum (380 - $700 \mathrm{~nm})$ of pure water, II, Integrating cavity measurements, Appl. Opt., 36(33), 8710-8723.

Prézelin, B. B. (1991), Diel periodicity in phytoplankton productivity, Hydrobiology, 238, 1 - 35.

Prézelin, B. B., and B. A. Boczar (1986), Molecular bases of cell absorption and fluorescence in phytoplankton: Potential applications to studies in optical oceanography, Prog. Phycol. Res., 4, 349 - 464.

Prézelin, B. B., R. R. Bidigare, H. A. Matlick, M. Putt, and B. VerHoven (1987), Diurnal patterns of sizefractioned primary productivity across a coastal front, Biol. Morya Vladivostok., 96, 563 - 574.

Prézelin, B. B., H. E. Glover, B. VerHoeven, D. K. Steinberg, H. A. Matlick, O. Schofield, N. B. Nelson, M. Wyamn, and L. Campbell (1989), Blue-green light effects on light-limited rates of photosynthesis:

Relationship to pigmentation and productivity estimates from the Sargasso Sea, Mar. Ecol. Prog. Ser., 54, $121-136$. 
Ryther, J. H., and D. W. Menzel (1959), Light adaptation by marine phytoplankton, Limnol. Oceanogr., $4(4), 492-497$.

Sakshaug, E., A. Bricaud, Y. Dandonneau, P. G. Falkowski, D. A. Kiefer, L. Legendre, A. Morel, J. Parslow, and M. Takahashi (1997), Parameters of photosynthesis: Definitions, theory and interpretation of results, J. Plankton Res., 19(11), 1637 - 1670.

Sathyendranath, S., V. Stuart, B. D. Irwin, H. Maass, G. Savidge, L. Gilpin, and T. Platt (1999), Seasonal variations in bio-optical properties of phytoplankton in the Arabian Sea, Deep Sea Res., Part II, 46, $633-653$.

Schofield, O., B. B. Prézelin, R. R. Bidigare, and R. C. Smith (1993), In situ photosynthetic quantum yield, correspondence to hydrographic and optical variability within the southern California Bight, Mar. Ecol. Prog. Ser., 93, 24 -37.

Schofield, O., B. B. Prézelin, and G. Johnsen (1996), Wavelength dependency in photosynthetic parameters for two dinoflagellate species Heterocapsa pygmaea and Prorocentrum minimum: Implications for the bio-optical modeling of photosynthetic rates, J. Phycol., 32, 574- 583.

Schofield, O., T. Bergmann, W. P. Bisset, F. Grassle, D. Haidvogel, J. Kohut, M. Moline, and S. Glenn (2002), The long term ecosystem observatory: An integrated coastal observatory, IEEE J. Oceanic Eng., 27(2), $146-154$.

Schofield, O., et al. (2004), Inversion of the bulk absorption in the Mid-Atlantic Bight and its utility for water mass analysis in optically complex coastal waters, J. Geophys. Res., 109, C07S10, doi:10.1029/ 2003JC002071, in press.

Siegel, D. A., et al. (2001), Bio-optical modeling of primary production on regional scales: The Bermuda bio-optics project, Deep Sea Res., Part II, 48, 1865 - 1896.

Smith, R. C., B. B. Prézelin, R. R. Bidigare, and K. S. Baker (1989), Biooptical modeling of photosynthetic production in coastal waters, Limnol. Oceanogr., 38(4), 1524 - 1544.

Sosik, H. M. (1996), Bio-optical modeling of primary production: Consequences of variability in quantum yield and specific absorption, Mar. Ecol. Prog. Ser., 143, 225 - 238.

Sournia, A. (1974), Circadian periodicities in natural populations of marine phytoplankton: A review, Adv. Mar. Biol., 6, 325 -389.

Stramski, D., and A. Morel (1990), Optical properties of photosynthetic picoplankton in different physiological states as affected by growth irradiance, Deep Sea Res., 37, 245 -266. 
Vodacek, A., N. V. Blough, M. D. DeGrandpre, E. T. Peltzer, and R. K. Nelson (1997), Seasonal variation of CDOM and DOC in the middle Atlantic Bight: Terrestrial inputs and photooxidation, Limnol. Oceanogr., 42(4), $674-686$.

Walsh, J. J. (1978), Wind events and food chain dynamics within the New York Bight, Limnol. Oceanogr., 23(4), $649-683$.

Ward, J. H. (1963), Hierarchical grouping to optimize an objective function, J. Am. Stat. Assoc., 58, 236 -244 .

Waters, K. J., R. C. Smith, and J. Marra (1994), Phytoplankton production in the Sargasso Sea as determined using optical mooring data, J. Geophys. Res., 99(C9), 18,385 -18,402.

Wright, S. W., S. W. Jeffrey, R. F. C. Mantoura, C. A. Llewellyn, T. Bjornland, D. Repeta, and N. Welschmeyer (1991), Improved HPLC method for the analysis of chlorophylls and carotenoids from marine phytoplankton, Mar. Ecol. Prog. Ser., 77, 183 - 196.

Zimmerman, R. C., J. B. SooHoo, J. N. Kremer, and D. Z. D’Argenio (1987), Evaluation of variance approximation techniques of non-linear photosynthetic-irradiance models, Biol. Morya Vladivostok, 95, $209-215$. 


\section{Figures}

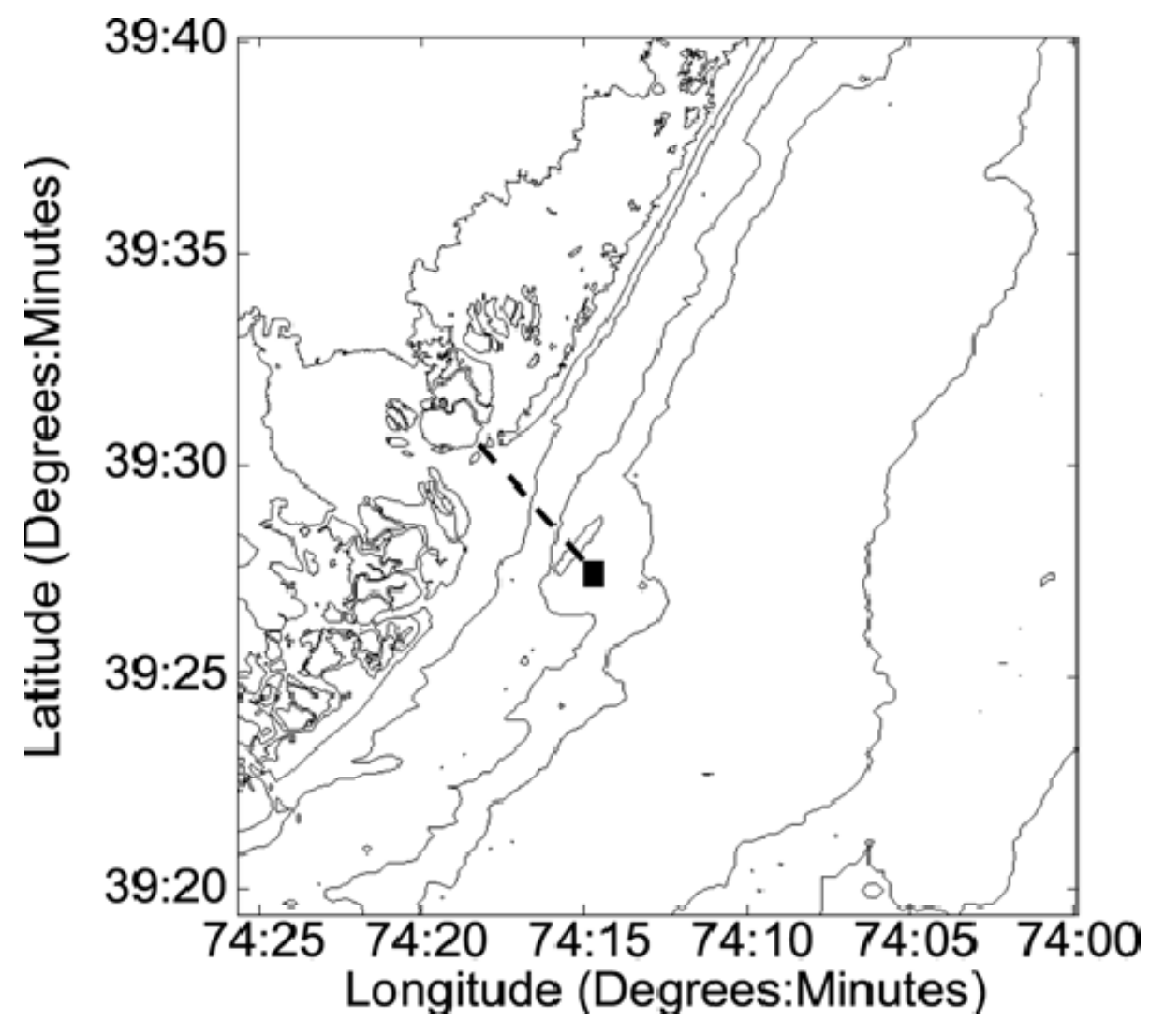

Figure 1. Location of node B and optical profiler connected via electro-optical cable (dashed line) to the Rutgers Marine Field Station located in the Mullica River estuary. Bottom contours are the 5-m isobaths. 


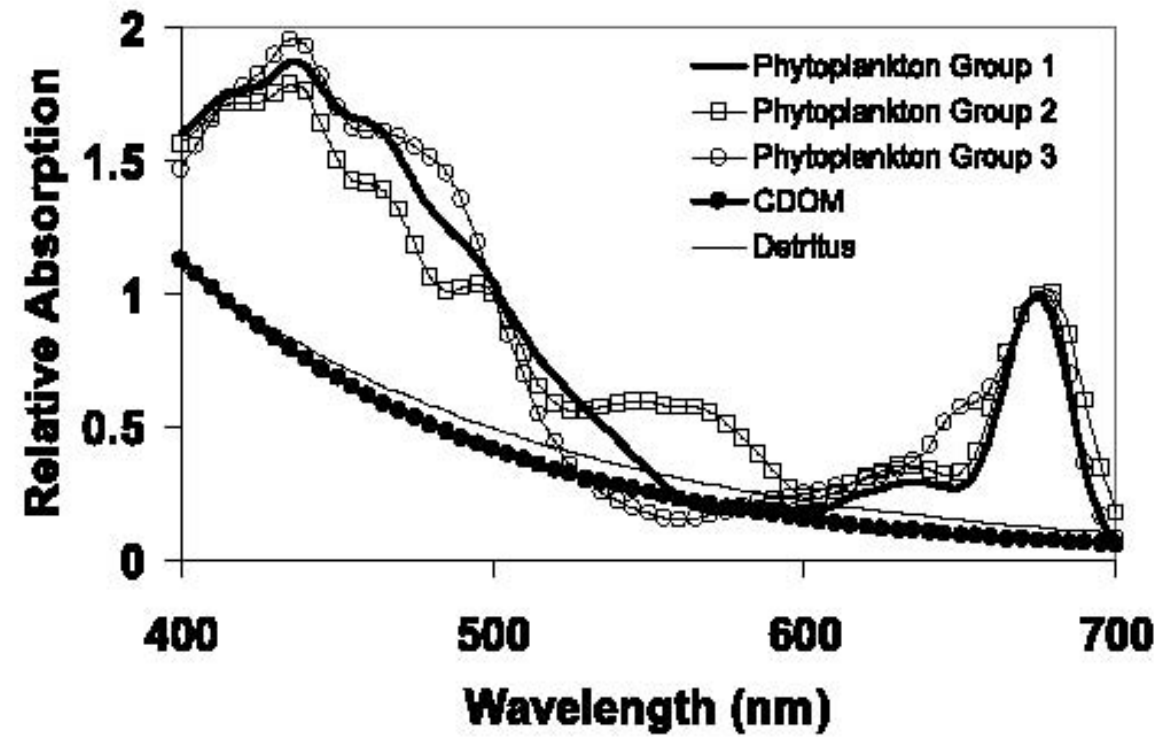

Figure 2. Input spectra used to invert the in situ absorption values measured by the ac- 9 using the OSI model. Phytoplankton spectra are averages of high-lightand low-light-adapted phytoplankton from Johnsen et al. [1994]. Phytoplankton group one represents chlorophylla-c containing classes of Bacillariophyceae, Dinophyceae, and Prymnesiophyceae. Phytoplankton group 2 represents the phycobilin-containing class Cryptophyceae. Phytoplankton group 3 represents the chlorophylla-b containing classes of Chlorophyceae, Prasinophyceae, and Eugelnophyceae. CDOM and detritus spectra are idealized exponential functions. 


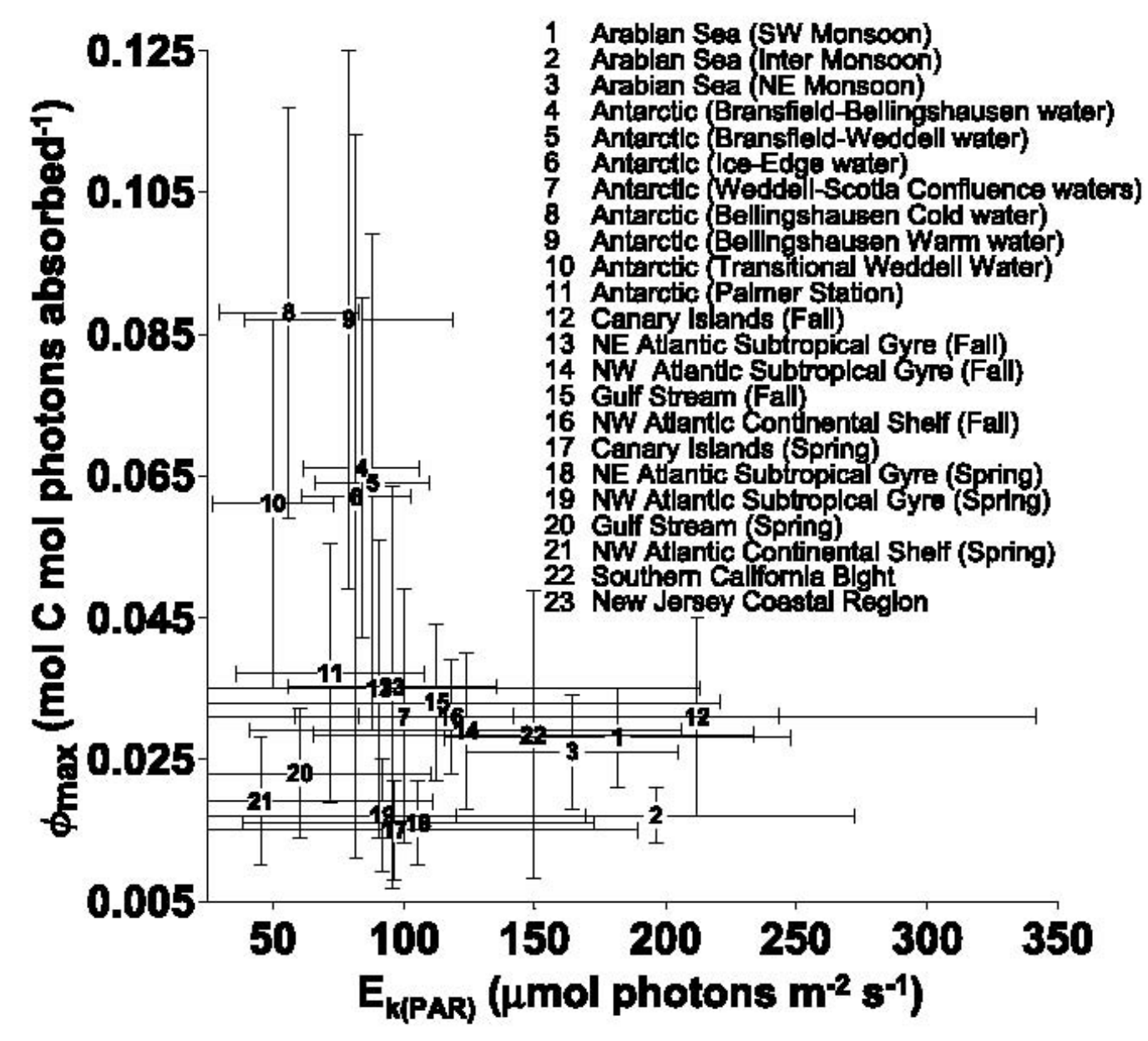

Figure 3. Paired $\mathrm{E}_{\mathrm{k}(\mathrm{PAR})}$ and fmax reported water column means and standard deviations from various studies: 1-3, Sathyendranath et al. [1999]; 4-7, Figueiras et al. [1999]; 8-10, Lorenzo et al. [2002]; 11, Moline and Prézelin [1996]; 13-21, Kyewalyanga et al. [1998]; 22, Schofield et al. [1993]; and 23 New Jersey Coastal Region (LEO). Antarctic studies are characterized by low $\mathrm{E}_{\mathrm{k}(\mathrm{PAR})}$ and high $\Phi_{\max }$, while the opposite trend is evident for tropical and temperate waters. The mean values for this study for $\mathrm{E}_{\mathrm{k}(\mathrm{PAR})}$ and $\Phi_{\max }$ were calculated from all the literature studies in temperate and tropical waters except those estimated at the study site using 14C incubations (all values not labeled "Antarctic" or "New Jersey Coastal Region (LEO)"). 


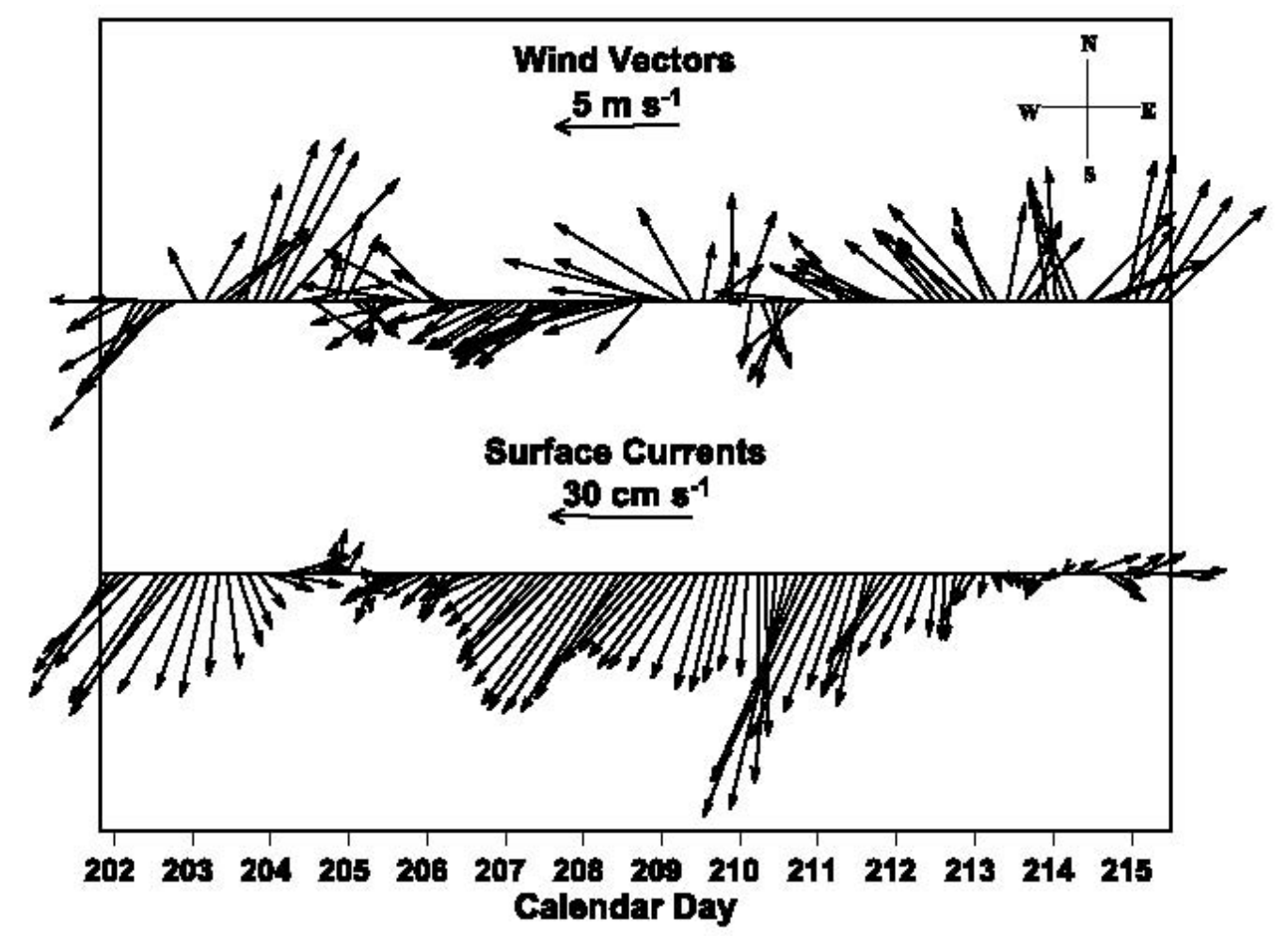

Figure 4. Three-hour-averaged wind velocities measured at RUMFS and surface currents measured over the profilers during their deployment. Surface currents are detided and loss-pass filtered. Vector speed is indicated by length. 

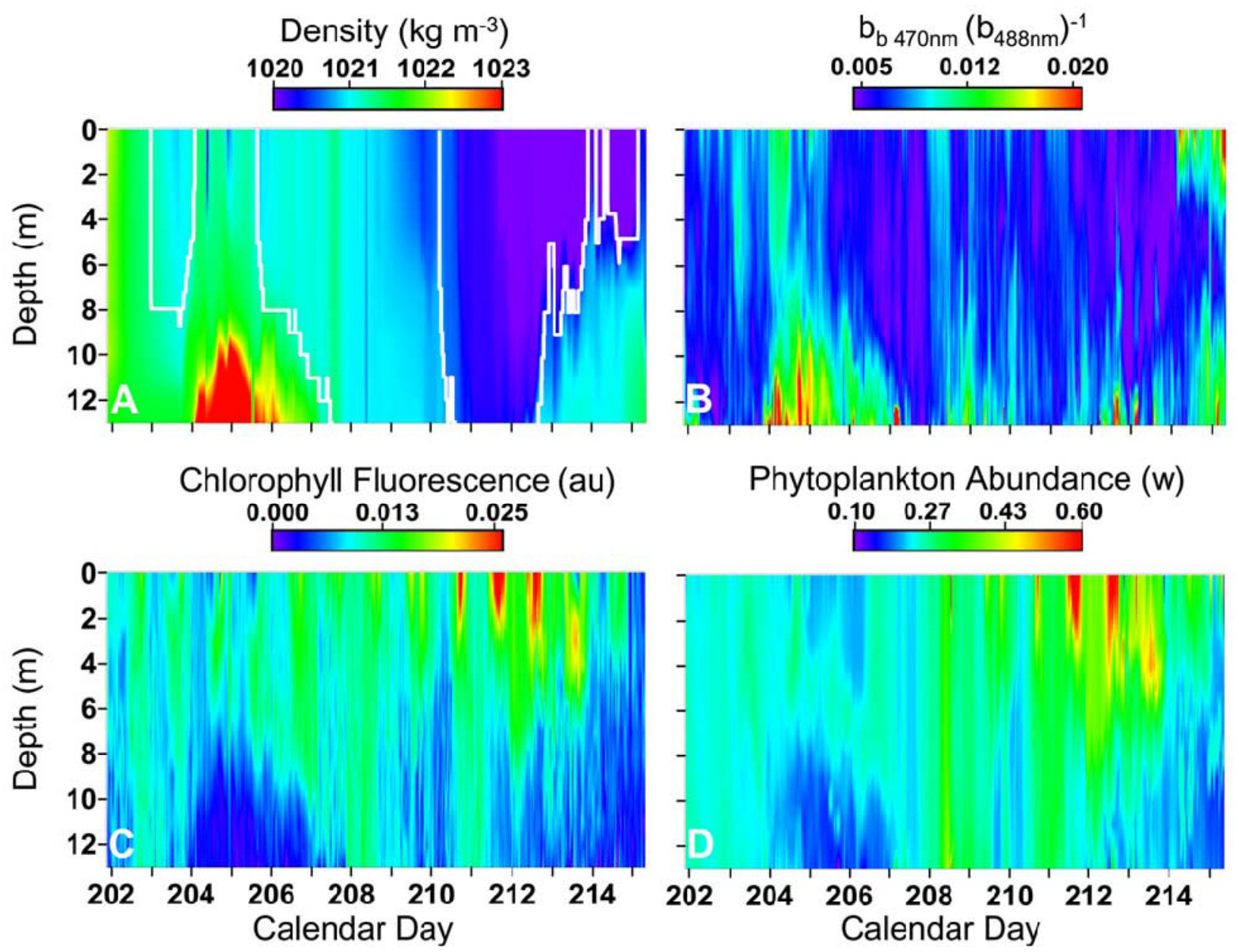

Figure 5. Time series of in situ data taken by the profilers during the experiment. (a) Density structure with water mass boundaries (white) defined by cluster analysis (see text). (b) The ratio of scattered and backward scattered light. (c) Chlorophyll fluorescence measured by the optical profiler. (d) The OSI-derived calibrated relative phytoplankton abundance. Optical and biological parameters have similar patterns as the hydrographic structure. Relationships between these bulk optical and derived optical parameters and the density structure are found in Table 2 . 

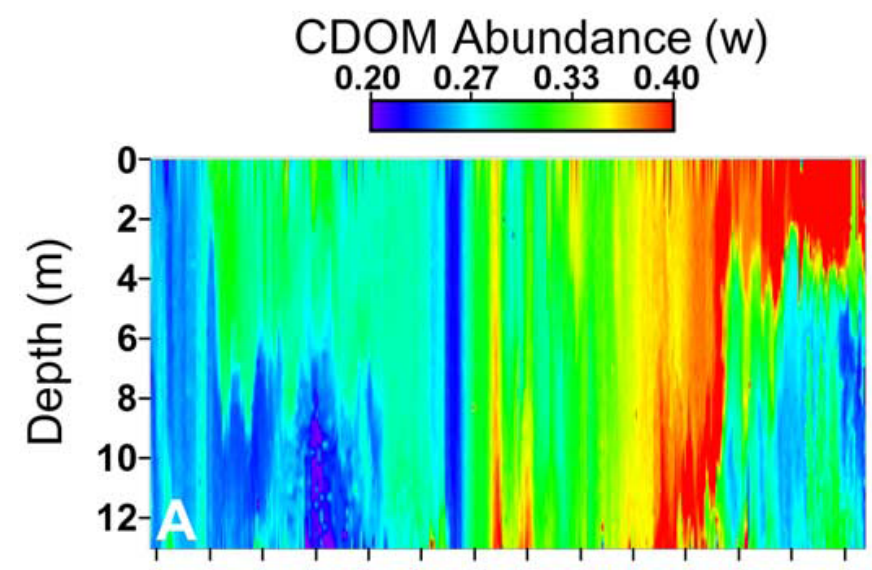

Detritus Abundance (w)

$\begin{array}{llll}0.20 & 0.27 & 0.33 & 0.40\end{array}$

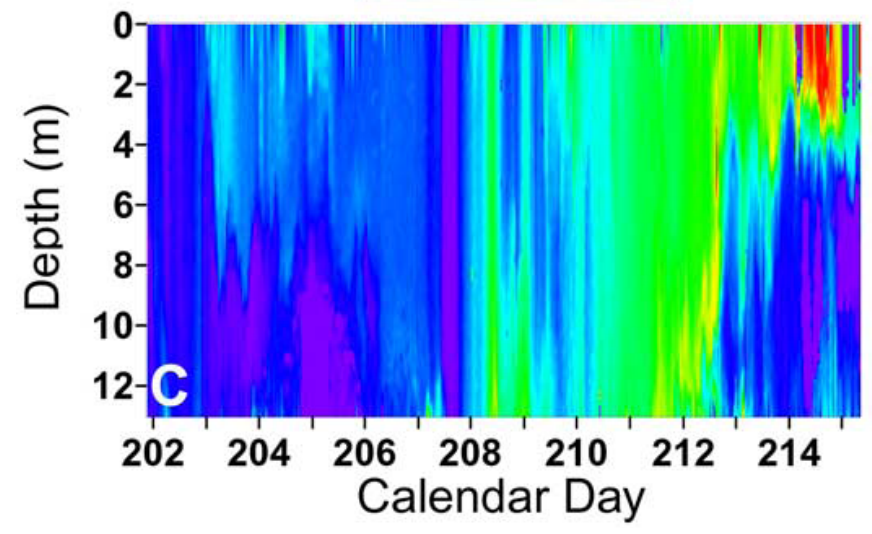

CDOM Slope
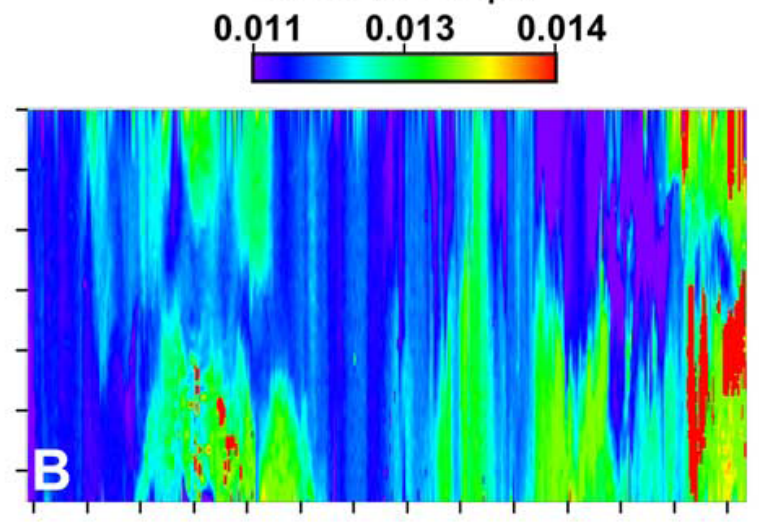

Detritus Slope
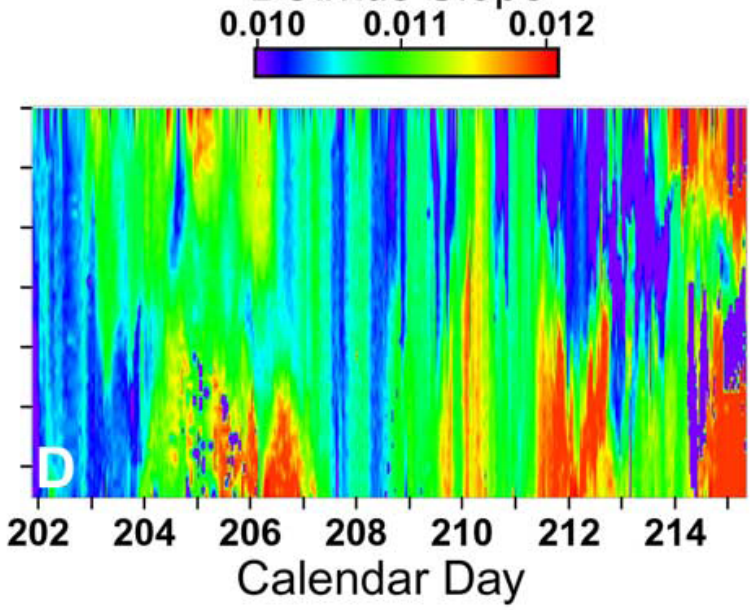

Figure 6. Time series of inverted in situ absorption data taken by the optical profiler during the experiment. (a) The relative abundance of CDOM and (b) the exponential slope of the CDOM curve. (c) The relative abundance of detritus and (d) the exponential slope of the detritus curve. Derived optical properties show distinct characteristics of the hydrographic structure during the experiment. Relationships between these derived optical parameters and the density structure are found in Table 2. 

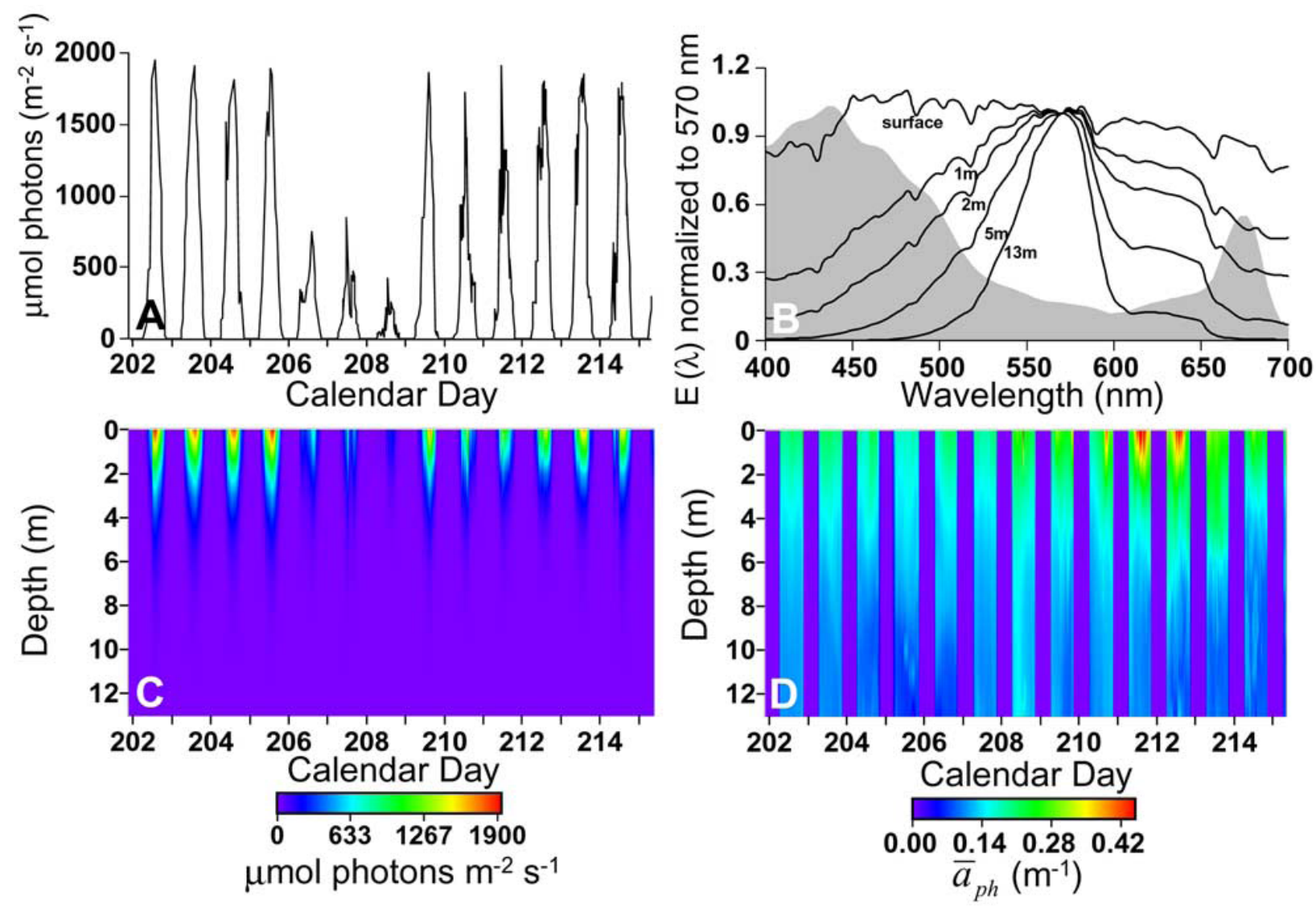

Figure 7. (a) The time series of incident $E_{d(P A R)}$ at the profilers. Noontime values of $E_{k(P A R)}$ varied by a factor of 4 because of passing storms. (b) A representative normalized profile of $E_{d}(\lambda)$ at the surface and $\mathrm{E}_{\mathrm{o}}(\lambda)$ at specific depths (solid lines) compared to the mean spectral shape of phytoplankton groups 1,2 , and 3. (c) The propagation of $E_{o(P A R)}$ through the water column. $\mathrm{E}_{\mathrm{o}(\mathrm{PAR})}$ values attenuated quickly because of the turbid nature of the region. The rapid attenuation of the blue wavelengths by CDOM and detritus and red wavelengths by water illustrate the mechanism for modulating $\mathrm{a}_{\mathrm{ph}}$ with depth. (d) The distribution of $\mathrm{a}_{\mathrm{ph}}$ during the experiment. Larges values are coincident with the largest biomass signal. Nighttime profiles were assumed to be zero. 


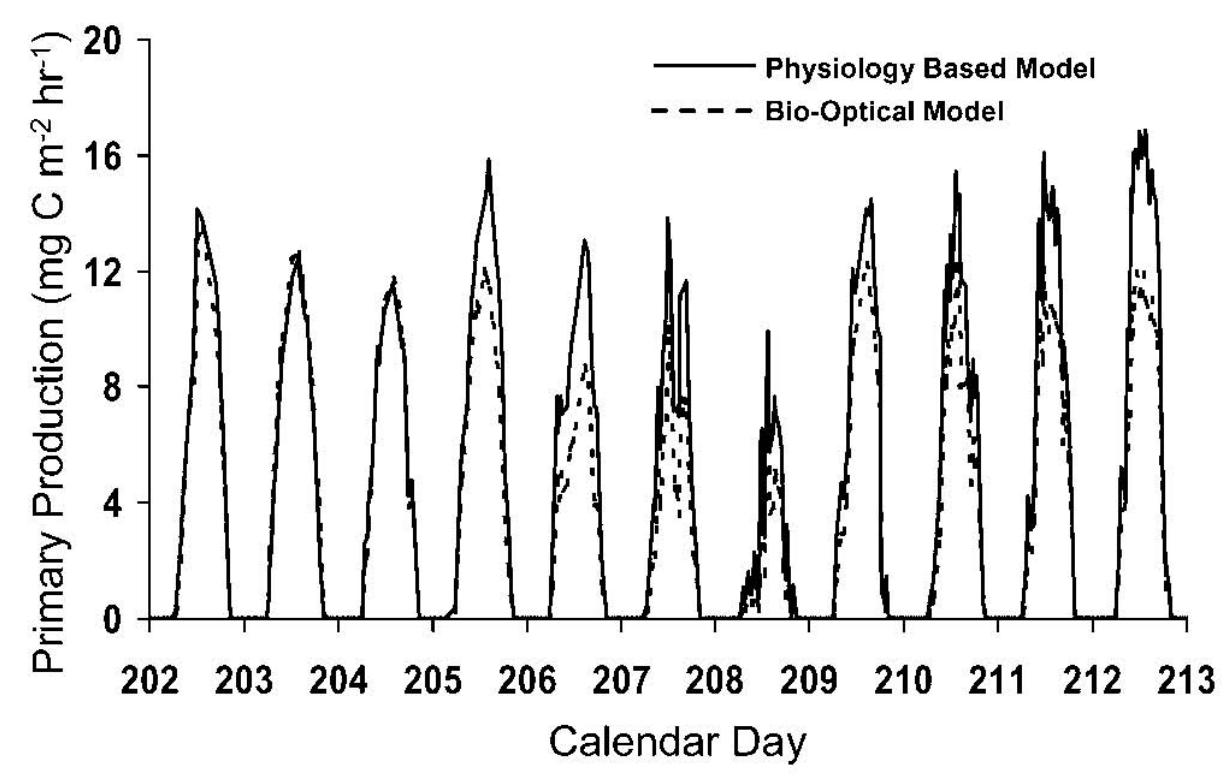

Figure 8. Using mean-paired $\mathrm{E}_{\mathrm{k}(\mathrm{PAR})}$ and $\Phi_{\max }$ from temperate and tropical oceans excluding this study, biooptically modeled (dashed) and physiology-based productivity that was extrapolated on the basis of the water mass analysis (solid) was in good agreement across all days $\left(\mathrm{r}^{2}=0.91, \mathrm{p}<\right.$ $0.001)$. The total productivity predicted by the two models was different by $20 \%$. 

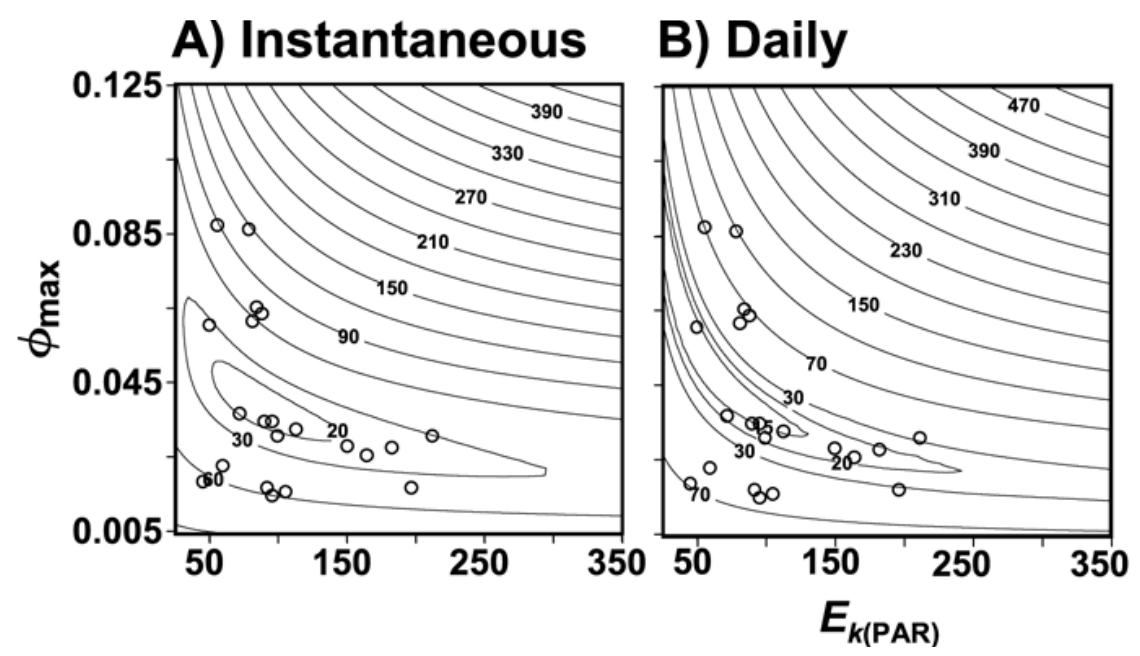

C) 11 Day

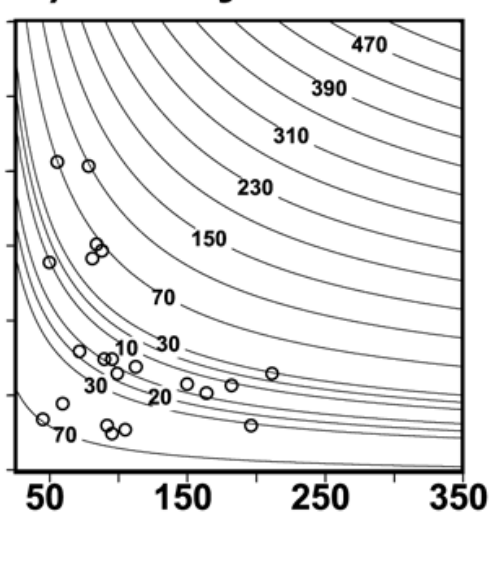

Figure 9. (a)-(c) Relative percent error isoclines between the 14C extrapolated to the ac-9-based water-column-integrated productivity estimates over instantaneous, daily, and 11-day timescales, respectively. The shape of these contours shows the effect of fmax and $E_{k(P A R)}$ covariance on modeled productivity estimates. Data points represent literature means from Figure 3 and are coincident with the error isoclines. 